\title{
Empyema thoracis: new insights into an old disease
}

\author{
F.J.H. Brims*,\#, S.M. Lansley", G.W. Waterer" and Y.C.G. Lee ${ }^{\#, \uparrow}$
}

ABSTRACT: Pleural infection is a disease of historical importance and is still a modern menace, with incidences rising in adults and children, and a significant mortality in adults. Basic research is hampered by limitations with in vivo models, and the bacteriology of empyema is complex. The role of thoracic ultrasound in guiding investigation and drainage of empyema is clear. Prompt treatment with appropriate systemic antibiotics and chest tube drainage are the key; in cases of failure of these measures, thoracic surgery is of proven efficacy in the treatment of this age-old disease.

\section{KEYWORDS: Empyema, infection, mesothelial, pleural, pneumonia}

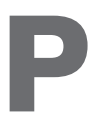

leural infection is one of the oldest and severest diseases. Drainage of the pleural cavity was attempted by Hippocrates over 2,000 years ago to treat empyema. During the influenza pandemic of 1917-1919, closed pleural drainage became widely practiced to treat postpneumonic empyema [1]. Throughout history, many famous physicians, such as Dr Guillaume Dupuytrens and Sir William Osler, have died from empyemas. Rapid recognition of the development of empyema is crucial to successful treatment; even with appropriate therapeutic attempts, the mortality of patients with empyema is $15-20 \%[2-4]$ and higher in immunocompromised patients [5].

The definition of empyema is pus in the pleural space [6], although most clinical trials and studies use the term pleural infection to encompass both empyemas and complicated parapneumonic effusions. It can affect any age group, sex and ethnicity and over 65,000 patients suffer from a pleural infection each year in the UK and USA [7], with an estimated hospital cost of 500 million USD. The incidence of empyema is rising in both developed and developing countries, including in paediatric populations. In Scotland, the incidence of empyema has risen 10 times in 1-4 yr old children since 1998 [8], with similar reports from the USA, Canada and elsewhere in Europe, and the trend is mirrored in adults [9-12]. The prevalence of HIV / AIDS, wider use of immunosuppressants and organ transplantation, and increasing age of the population mean pleural infection will continue to remain a common and significant illness.
Pleural infection can also complicate thoracic (open or closed) trauma and iatrogenic procedures, such as surgery (especially lung resection) or oesophageal rupture. "Spontaneous" bacterial empyema is rare. It is possible that genetic predisposition contributes to development of empyema in some patients [13]. Despite numerous studies the best management of pleural infection remains controversial with widespread variations in practice [14].

This review will examine novel themes of translational research, highlighting areas of clinical importance and fields in need of further investigation, as well as evaluating the current best clinical management of pleural infection.

\section{PATHOGENESIS}

\section{Animal models of pleural infection}

Pleural infection remains difficult to treat in part, as the underlying disease mechanisms are poorly elucidated. Basic laboratory research in pleural infection is hampered by a lack of suitable in vivo models. Attempts have been made using a variety of species, including mice, rats, rabbits, guinea pigs and sheep, to develop a clinically reliable model of empyema. Many models require injury to the pleura to precede pathogen instillation [15-19], as direct bacterial administration into the pleural space often results in their complete clearance [20] or severe sepsis [21]. Other studies have suggested that a pleural effusion is required as a substrate for bacterial growth $[22,23]$. One commonly used method involves the intrapleural injection of turpentine, which results in pleural inflammation and an exudative effusion, prior to

\section{AFFILIATIONS}

*Respiratory Dept, Portsmouth Hospitals NHS Trust, Portsmouth, UK.

\#Respiratory Dept, Sir Charles Gairdner Hospital, Perth, and "School of Medicine and Pharmacology and Lung Institute of Western Australia, University of Western Australia, Perth, Australia.

CORRESPONDENCE

Y.C.G. Lee

University Dept of Medicine, 4/F, G Block

QE II Medical Center

Perth

WA 6009

Australia

E-mail: gary.lee@uwa.edu.au

Received:

May 252010

Accepted:

May 272010

PROVENANCE

Publication of this peer-reviewed article was supported by GlaxoSmithKline, Belgium (principal sponsor, European Respiratory Review issue 117).

European Respiratory Review Print ISSN 0905-9180

Online ISSN 1600-0617 
the introduction of pathogens [18]. This approach, however, has variable efficacy [19] and turpentine itself may influence the results. Intrapleural injection of Pasturella multocida (a common respiratory tract pathogen in rabbits) in brain-heart infusion agar into rabbits has been shown to reliably induce empyema [20]; however, death from overwhelming sepsis frequently complicates this model unless systemic antibiotics are administered.

The technical issues associated with the current animal models of empyema preclude their use in large scale in vivo research. The aforementioned models differ from common clinical scenarios in that empyema is induced in the absence of concurrent pneumonia. The use of animal-specific pathogens and the need to administer antibiotics also limit the translational relevance of these models.

\section{Effect of bacteria on mesothelial cells in vitro}

In the absence of faithful animal models, most research on infection of serosal (pleural and peritoneal) cavities have been in vitro based. Numerous studies have described the potent biological effects of bacteria, live or attenuated, on both pleural and peritoneal mesothelial cells. The mesothelial cell responses appear to be dependent on both the state and type of microbial species and the origin of the mesothelial cells. Direct exposure of mesothelial cells to different types of bacteria have been shown to affect inflammatory responses, coagulation and fibrinolysis processes, resulting in a unique mesothelial cell activation signature [24]. For example, the presence of heatkilled Escherichia coli increases elaboration of inflammatory cytokines such as interleukin (IL)-6, IL-8, RANTES (regulated upon activation, normal T-cell expressed and secreted) and monocyte chemotactic protein-1 (MCP-1) from mesothelial cells, whereas heat-killed Staphylococcus aureus increases IL-6 and IL- 8 but not RANTES or MCP-1 [25]. Variable activation was also observed in a separate study comparing the IL-8 response of peritoneal mesothelial cells cultured with live or heat-killed S. aureus, Staphylococcus epidermidis and E. coli or bacterial culture supernatants [26]. The live S. aureus and live $S$. epidermidis isolates induced mesothelial cell production of IL-8, but the live E. coli or any of the heat-killed or bacterial culture supernatants did not, suggesting that heat alteration of the bacterial cell wall component may play a role [26]. Peritoneal mesothelial cells have also been shown to ingest and kill live isolates of S. aureus, S. epidermidis and E. coli [27, 28]. While ingestion of Staphylococci was low, E. coli were digested within $8 \mathrm{~h}$, resulting in mesothelial cell disintegration and bacterial proliferation [28].

\section{Development of a parapneumonic pleural effusion and fibrinogenesis}

Lung parenchymal infection stimulates local pleural immune activation, neutrophil migration and release of pro-inflammatory cytokines, such as IL- 6 , IL- 8 and tumour necrosis factor (TNF)- $\alpha$ [29-31]. These mediators induce changes in the permeability of the mesothelial cell monolayer, which contributes to fluid accumulation in the pleural space. Murine studies of infection with $S$. aureus suggest pleural mesothelial cells express early response genes c-fos and c-jun, followed by the expression of pro-apoptotic genes Bak and Bad during late stage infection [32]. This leads to pleural mesothelial cell apoptosis and loss of monolayer integrity, which may contribute to loss of the normal fibrinolytic milieu of the pleural space with conversion to a more pro-fibrinogenic, antifibrinolytic environment, with release of TNF- $\alpha$ from mesothelial cells [33] and concurrent upregulation of antifibrinolytic mediators, such as plasminogen activator inhibitor-1 and -2 [33]. Infection of mesothelial cells with live mycobacteria bacille Calmette-Guerin (BCG) results in enhanced vascular endothelial growth factor release [34] and both live BCG and S. aureus infection increase permeability across the mesothelial monolayer, in part via downregulation of $\beta$-catenin [34, 35]. With persistent inflammation, increased vascular and mesothelial permeability leads to increased plasma extravasation into the pleural cavity. Activation of the coagulation cascade within the pleural cavity contributes to the development of a "fibrinopurulent" or "complicated" parapneumonic effusion, with fibrin deposition over both pleural surfaces and characteristic fibrinous septae producing loculated effusions [36].

\section{MICROBIOLOGY}

The prevalence of different causative organisms of pleural infection varies among countries; local epidemiological data are needed to guide treatment. Series from the UK, Canada and New Zealand all demonstrate that Streptococcus milleri is the most common isolate in adults with community-acquired empyema, with proportions ranging between 32 and $50 \%$ of cases [4, 37, 38]. The other common isolated organisms of empyema are Streptococcus pneumoniae and anaerobes for community-acquired pleural infection and S. aureus (including methicillin-resistant $S$. aureus (MRSA)) for hospital-acquired cases [36]. A more recent report from Taiwan has confirmed a higher incidence of aerobic Gram-negative and anaerobic infections in those with empyema from hospital-acquired pneumonia [37].

S. milleri is part of the viridans streptococci group that comprises a heterogeneous group of facultatively anaerobic, Gram-positive cocci that do not produce catalase or coagulase [39]. S. milleri is a typically benign commensal that is part of the normal flora of the human orophayrnx, and it is rarely isolated in community-acquired pneumonia [40, 41], which makes its apparent virulence in empyema seem incongruous. Some reports suggest patients with $S$. milleri empyema more commonly have comorbidities, such as underlying malignancy or diabetes mellitus [42, 43], and mortality with S. milleri empyema has been reported to be up to one fifth of cases [43]. A retrospective study of 72 patients in Taiwan identified that in $63 \%$ of cases anaerobes were co-isolated with S. milleri [43]. It has been demonstrated in murine models of pulmonary infection that there may be synergy between $S$. milleri and anaerobes with greater histopathological abnormalities of pneumonia and higher mortality in the mixed infection group $[44,45]$. Furthermore, viable bacteria were more numerous in the lungs of mice with mixed infections than in the lungs of those with single microbial infection. Accompanying in vitro studies suggested anaerobes may enhance the growth of the $S$. milleri group and/or inhibit the bactericidal activity of the host. Further research is required to better elucidate and understand the mechanisms by which this common bacteria causes pleural infection in humans. 
The yield of bacterial culture of pleural fluid in empyema is low $(\sim 60 \%)$ with conventional laboratory methods [37, 46]. Different postulations have been made to explain this observation. It may simply represent effective antibiotic treatment prior to sample collection. Alternatively, it may suggest that continual presence of bacteria is not necessary to sustain the ongoing inflammatory response after the initial bacterial invasion. Lack of sensitivity of conventional cultural techniques, presence of biofilms in the pleura and other hypotheses are also being examined.

\section{Pneumococcal serotypes}

In paediatric empyema series, S. pneumoniae is the most common organism and can account for up to $51 \%$ of cases $[47,48]$. Interestingly, the incidence of paediatric empyema continues to rise despite the introduction of the pneumococcal vaccine, raising intriguing questions.

The heptavalent pneumococcal conjugate vaccine (PCV-7) for children, released in the late 1990s, targets pneumococcal strains 4, 6B, 9V, 14, 18C, 19F and 23F [49], which are traditionally associated with invasive pneumococcal disease, including empyema [50]. PCV-7 reduces nasopharyngeal carriage [51-53] and the likelihood of community spread [54], resulting in a decrease in invasive pneumococcal disease in children [55], but also a reduction in adult invasive disease of the strains covered by the PCV-7 [55, 56]. The adult benefit from the PCV-7 programme in children continued to be observed for several years after its introduction in the USA [50].

It is, therefore, puzzling why many countries, including the USA [9], Spain [10], Israel [57] and Belgium [11], have reported a marked increase in the incidence of empyema in children with pneumonia. A similar trend to increasing incidence of empyema since 2000 has also been observed in adults [58], with a three- to five-fold increase in empyema incidence reported by groups in the USA [9] and Spain [10]. As postpneumonic empyema is much more common in children than adults $[59,60]$, it is logical that a change in incidence would be detected more quickly in this age group.

Determining the extent to which PCV-7 is responsible for the observed increase in empyema is problematic. While pneumococci are the most commonly identified cause of empyema in children and adults, $S$. aureus, including methicillin-resistant strains, are being reported with increased frequency in both adults [58] and children [61]. In some centres there was also clearly an increasing rate of empyema before the introduction of PCV-7 [59-61], suggesting that there may have been a shift in virulence of empyema-causing pneumococcal strains prior to vaccine introduction. However, in the reports of increasing empyema incidence after PCV-7, the non-vaccine serotype 1 has usually been the most commonly identified pneumococcus $[58,59,62,63]$.

Overall, it appears that there may have been a change in the invasive properties of empyema-causing pneumococcal serotypes prior to the introduction of PCV-7. Even without a change in virulence, the historically empyema-prone serotypes, predominantly 1 and 3, are not covered by PCV-7, so the widespread adoption of the vaccine has favoured their spread by reducing their natural competition. The 10-, 11-, and 13valent PCV in development will cover the new non-PCV-7 strains that have become dominant. It will be intriguing to observe how this may alter the incidence of empyema and what new pathogens may fill the niche vacated.

\section{CLINICAL FEATURES}

The clinical manifestations of parapneumonic effusion vary according to the underlying infection; in the UK-based Multicentre Intrapleural Sepsis Trial (MIST) of 430 patients, the median (interquartile range) duration of symptoms prior to recruitment was 14 (8-28) days [4]. Aerobic pneumonic infections will tend to present with an acute febrile illness, localised pleuritic chest pain, sputum production and leukocytosis. Infections with anaerobes tend to lead a more insidious clinical course with, less pronounced fever and more generalised systemic symptoms, such as poor appetite and weight loss; such infections are more common in those with poor dental hygiene, in alcoholics and in those who have had a period of unconciousness leading to aspiration of gastric contents [64].

Exudative simple parapneumonic effusions can occur in as many as $40 \%$ of patients with pneumonia [65], and may frequently resolve with appropriate antibiotic treatment of the pneumonia, without the need for drainage. The diagnosis of pleural infection is often delayed [66] and a high clinical suspicion is required to make an early and accurate diagnosis of a parapneumonic effusion. Pleural infection should be suspected in all patients with pneumonia, in particular those who fail to respond to appropriate antibiotic therapy, as defined by persistent fever, leukocytosis and raised inflammatory markers such as C-reactive protein. Immunosuppressed hosts and the elderly can present with disproportionately mild symptoms (relative to the severity of the pleural infection). The size of the effusion varies, and cannot be used to predict infective aetiology.

It is important to separate pleural infections that follow community-acquired pneumonia and hospital-acquired cases, as the causative bacteria are often different. Hospital-acquired empyema has a significantly worse outcome, with a mortality of up to 50\% [67], and must be treated urgently and aggressively.

\section{INVESTIGATION AND DIAGNOSIS \\ Radiological investigations}

Any patient presenting with pneumonic symptoms, or those who are failing to respond to appropriate therapy and/or who have a pleural-based opacity on chest radiograph that obscures the hemidiaphragm, should be considered for further imaging and investigation. A lateral chest radiograph may be useful in this instance, where the presence of pleural fluid is suggested when the posterior costophrenic angle is blunted, or the hemidiaphragm is not visible throughout its length [68].

Ultrasound of the thoracic cavity (fig. 1) can reliably demonstrate loculations and septations [69], and increases the success rate and reduces the complications of thoracentesis [70]. A recent retrospective study of 141 patients has demonstrated the appearance of sonographic septation to be a useful sign to help predict the outcome of small-bore catheter drainage in cases of empyema or complicated parapneumonic pleural effusion [71]. Patients with a complex septated sonographic pattern had a poorer prognosis for a successful outcome, higher ICU admission rate and a higher mortality rate. 


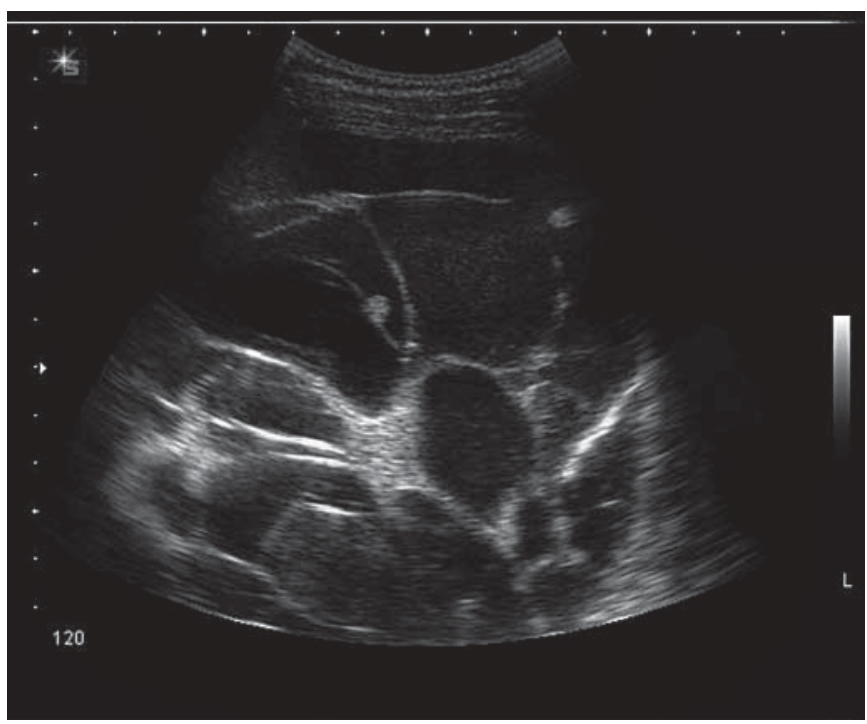

FIGURE 1. Ultrasound image of multiple septations and loculations in a patient presenting with a pneumonic illness and pleural effusion. Courtesy of $\mathrm{N}$ Rahman, Oxford University, UK.

Contrast-enhanced computed tomography (CT) of the chest (fig. 2) will provide detailed information on parenchymal infiltrate, the presence of pulmonary abscess and position of chest drains, although a study of 50 patients suggested that CT abnormalities do not predict the stage of the parapneumonic effusion, nor its likelihood of requiring surgical intervention [72]. Furthermore, radiological features on CT are not predictive of which patients require conversion to thoracotomy decortications from video-assisted thoracoscopic surgery (VATS), should surgery be required [73]. A recent study of paediatric empyema in 60 patients treated with percutaneous chest drains and urokinase examined the role of routine CT in this population and found that, while CT did demonstrate more parenchymal abnormalities, its use did not alter

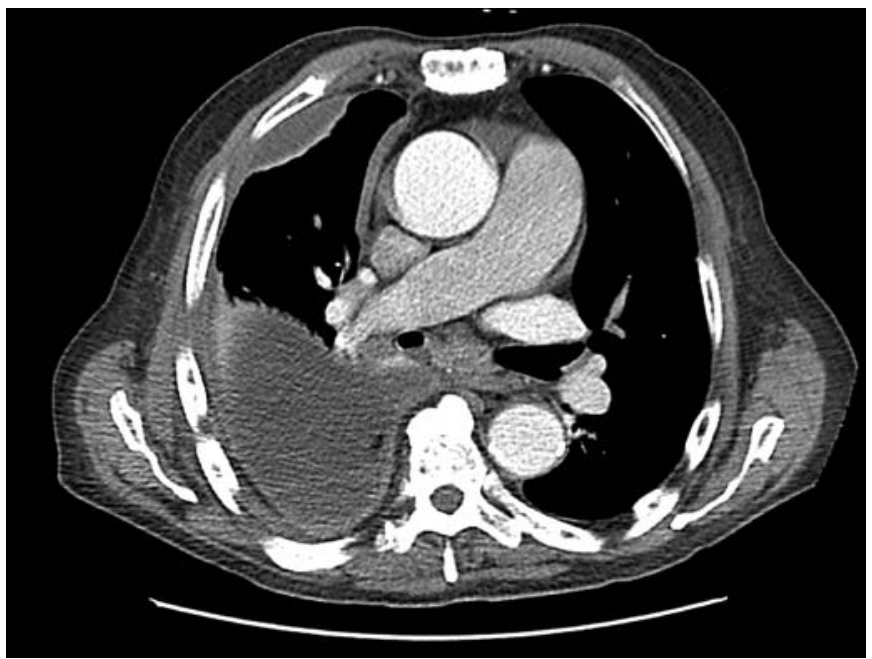

FIGURE 2. Contrast-enhanced computed tomography of the chest in a liver transplant patient on immunosuppression who developed pneumonia and complicated parapneumonic pleural effusion. management over and above ultrasound and chest radiograph [74]; as a result, the prevailing opinion suggests that in the paediatric population ultrasound should be routinely used, and CT only in special circumstances [75]. CT should be used when the diagnosis is in doubt and may also provide information on underlying abnormalities associated with the empyema, such as pulmonary abscesses, an oesophageal perforation or bronchogenic carcinoma. Rarely, depending on the clinical setting, additional investigations may be required, such as a barium swallow (fig. 3).

\section{Thoracocentesis}

Biochemical sampling of the pleural fluid is essential. Neutrophil phagocytic activity, with protease production and cell wall lysis, leads to a fall in $\mathrm{pH}$ of the pleural fluid [18] and concurrent fall in glucose, both characteristic biochemical features of complicated parapneumonic effusions and empyema [6, 76]. The increasing numbers of inflammatory cells within the pleural space lead to a rise in lactate dehydrogenase [77], often in excess of three times the upper limit of normal. A recent report has demonstrated that pleural fluid IL-8 can be an accurate discriminator of complicated and uncomplicated parapneumonic effusion [78], although the same report also demonstrated that pleural fluid $\mathrm{pH}$ was equivalent to IL-8 in such discrimination. As a result, $\mathrm{pH}$ remains the most useful in defining the need for pleural drainage [14, 79]. Accurate measurement of pleural fluid $\mathrm{pH}$ requires the use of blood gas analysers and careful collection without admixture of air or carried over lignocaine [80]. Pleural fluid glucose correlates with $\mathrm{pH}$ and can be an alternative if accurate $\mathrm{pH}$ analysis is not available.

Many other biomarkers have been investigated for the diagnosis of pleural infection from simple parapneumonic effusions or effusions of other aetiologies, e.g. procalcitonin and TREM-1 (triggering receptor expressed on myeloid cells 1) $[81,82]$. None of these markers have the accuracy to be used as a sole diagnostic tool. Also, they cannot replace conventional culture tests, as identification of the organism and antibiotic sensitivity are important to management.

Empyema is confirmed by the presence of frank pus, or positive microbial staining and/or culture of the pleural fluid. Diagnostic yield from culture will be increased with the innoculation of blood culture bottles with pleural fluid at the bedside [83] and the biochemical characteristics of the fluid in different locules may vary [84]. Bacterial PCR techniques have been applied to pleural fluids with promising results [46]. Recent evidence suggests that the use of a broad range 16S rDNA PCR may increase the chance of identifying pathogens (especially Gram-positive organisms) from pleural fluid [47, 48]. The use of PCR in adult empyema samples (with a wider range of organisms) has however, yielded mixed results, with significant false positives and negatives precluding its clinical use to date.

\section{MANAGEMENT}

\section{"If an empyema does not rupture, death will occur" - Hippocrates}

The principal aims are to control the infection and to evacuate the infected material. Once pleural infection is suspected, appropriate broad spectrum systemic antibiotics must be 

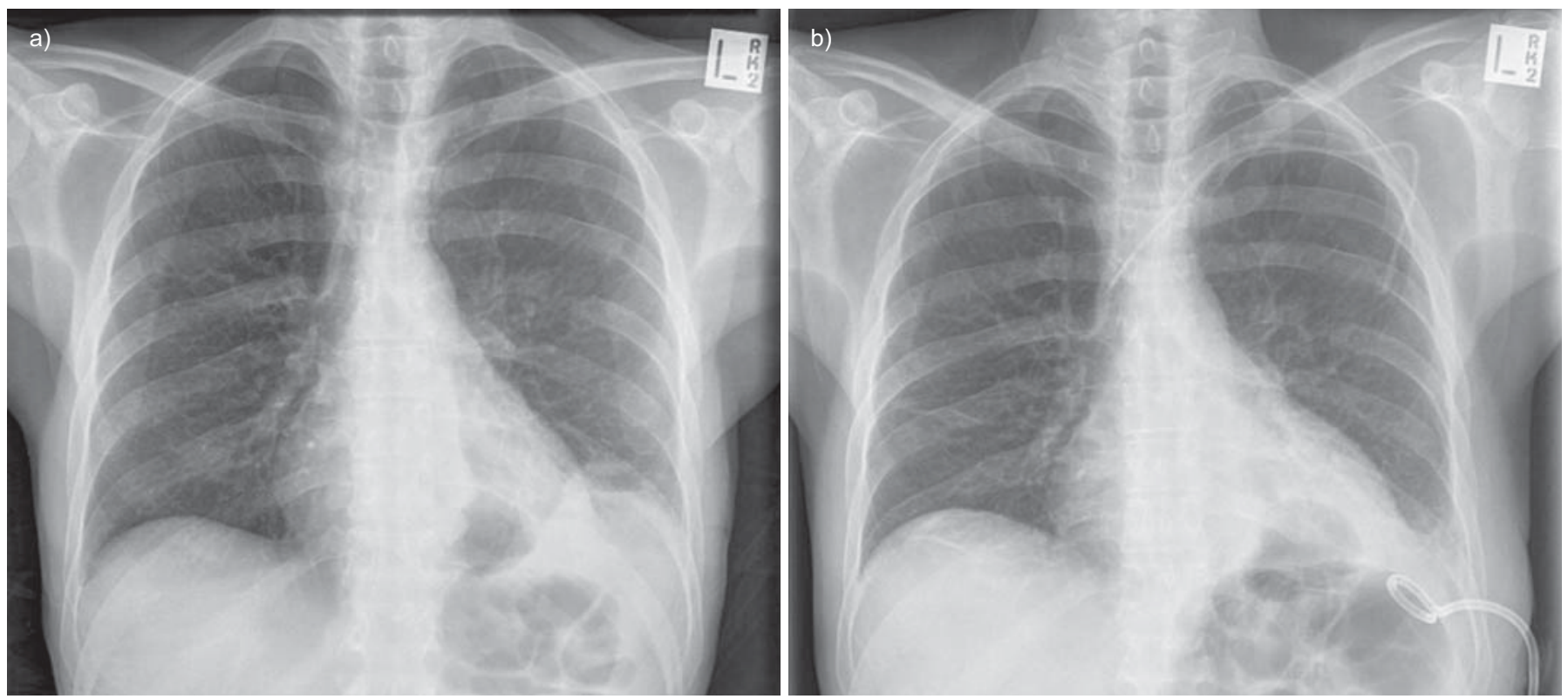

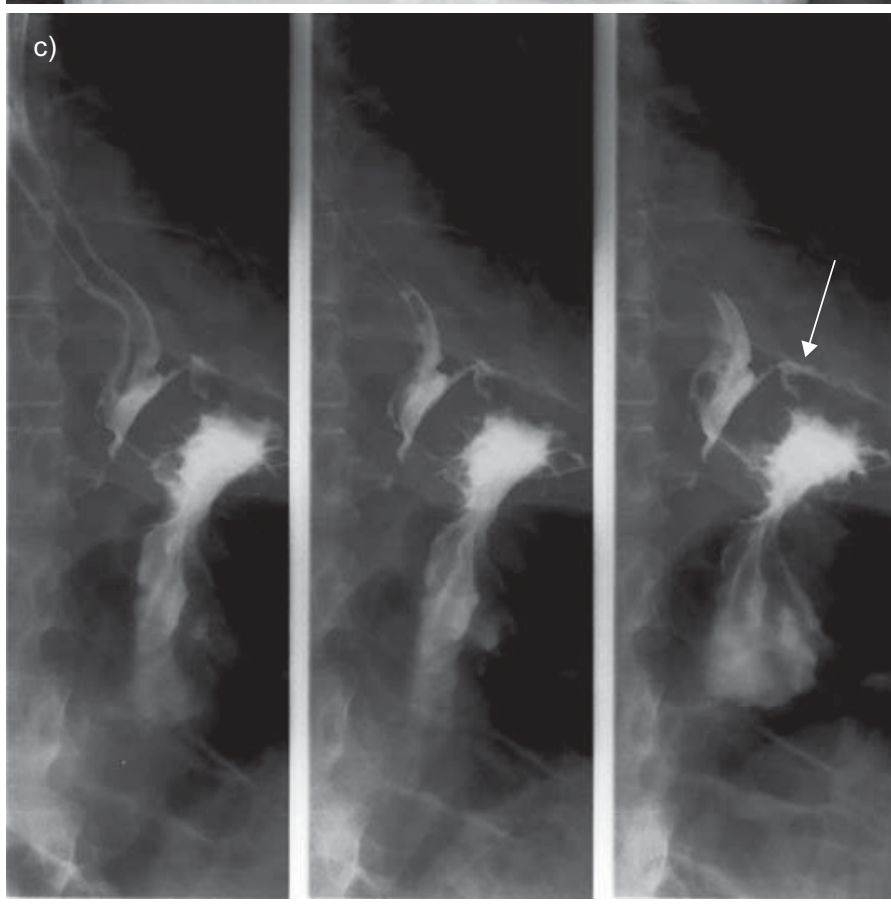

started without delay. Choice of antibiotics depends on the local bacteriology and pathogen resistance patterns. The British Thoracic Society guidelines recommend a combination of cefuroxime and metronidazole or co-amoxiclav for communityacquired empyema in adults and vancomycin plus meropenem for hospital-acquired cases (because of the high incidence of MRSA) [46, 85]. Our knowledge is very limited regarding the pharmacokinetics of antibiotic activity in the pleura following intravenous or oral delivery: a topic for urgent research, which is needed to guide choice of therapy.

Drainage is most commonly achieved using an intercostal catheter. As many patients with pleural infection have multiseptated pleural collections, imaging-guided chest tube placement often allows optimal placement of the drainage tube in
FIGURE 3. Oesophageal pleural fistula in a patient with Crohn's disease. a) A small left empyema, b) treated with small-bore chest drain; subsequent cultures grew mixed Gram-negative bacteria and yeast. c) Subsequent barium swallow demonstrates leak of contrast into left pleural space (arrow).

the largest collections of infected material, and are preferred over "blind" bedside insertion of chest tubes. Although largebore chest tubes were often advocated for pus drainage, several observational series suggested that small-bore catheters can be adequate $[71,86,87]$. In case of multiple large loculations, more than one catheter may be needed to achieve adequate pus evacuation. In the MIST study, no significant differences were found in the outcomes of patients who received large chest drains and those treated with small-bore catheters [4], although the assignment of catheters was not randomised. Blockage is more common with small-bore drains [88] and regular flushing of the drains may be necessary [89]. Small-bore catheter sets frequently contain an integral threeway tap, the internal diameter of which is often $\leqslant 9$ French gauge and thus act as the rate-limiting point for drainage. 
The use of indwelling small-bore pleural catheters for ambulatory drainage of chronic empyema has been shown to be successful in anecdotal cases [90]. Repeated (imagingguided) thoracentesis can theoretically be an alternative to chest tube drainage and has been shown to be effective in animal experiments as well as in one small clinical study [91]. The concept of lavaging the pleural space has also been explored [92] and some European centres advocate intrapleural infusion of saline several times a day to "wash out" the pleural space to reduce bacterial load. These approaches would require further evaluation.

\section{Intrapleural therapy}

Septations often prohibit complete evacuation of the pleural pus and the presence of septated empyema has been demonstrated to prolong hospital stay and chest tube drainage time, and to increase the need for surgery [93] and predict failure of tube drainage [94]. Fibrinolytics have been utilised in an attempt to lyse loculations in order to enhance drainage, and while initial studies have shown that intrapleural administration of streptokinase or urokinase significantly increases drainage volume, fibrinolytics do not improve patient outcome [95]. Animal studies have suggested that streptokinase can provoke fluid accumulation even in a normal pleural cavity, and may explain the dramatic (up to nine-fold) increase in pleural fluid drainage following fibrinolytic therapy $[87,96]$.

The largest study to date, a randomised double-blind trial of 430 patients showed that intrapleural streptokinase did not reduce mortality or the need for salvage surgical drainage [4], with similar findings echoed in a single-centre study from South Africa [97]. Use of other fibrinolytics, such as tissue plasminogen activator, either alone or combined with DNase (which reduces pus viscosity in vitro and in isolated case reports), have shown benefits in one small study of 20 adults [98], and have been assessed in a large UK randomised clinical trial, which is due to be reported shortly.

\section{Surgery for empyema}

Surgery should be considered without delay in patients who fail to improve with antibiotics and chest tube drainage, and who have persistent infective symptoms, fever, leukocytosis and raised inflammatory markers. Contrary to popular belief, radiological clearance of pleural collection is not a good indicator of disease progress. Two recent longitudinal studies have shown that radiological opacity of pleural infection improves in both adult and paediatric patients over the subsequent months, without the need for surgery [4, 97]. Likewise, restrictive changes in pulmonary function tests usually improve in parallel over time; very few patients have functional impairment from residual pleural fibrosis.

In several retrospective studies, those referred late for surgery had more complications and lower success rate from VATS, and longer hospital stay [99]. VATS is the procedure of choice, as it is equally effective but less invasive (and hence results in shorter hospital stay and fewer complications), than drainage by thoracotomy in both adults and children [99-101], although in up to $20 \%$ of patients, VATS is inadequate and conversion to open thoracotomy drainage is necessary [102]. Medical thoracoscopy has been shown to be safe and effective in one retrospective series of 127 patients [103]. A variety of surgical techniques have been utilised and a detailed description can be found elsewhere [104].

The role of "primary surgical treatment" as the first-line approach for empyema is unclear. To date, two randomised trials have compared primary VATS against conservative chest tube drainage in adult patients and neither showed any major clinical benefits, except for a slightly shorter hospital stay (mean \pm SD; $8.7 \pm 0.9$ versus $12.8 \pm 1.1$ days) [105, 106]. Two randomised trials in paediatric patients also failed to show significant advantages of surgery [102, 107], although both of these studies suggested lower treatment costs in the fibrinolysis groups, although these were secondary analyses. No significant cost differentials exist between primary VATS and conservative chest tube drainage in any formal published health economy analyses.

Treatment of underlying clinical predisposing factors, such as poor dentition or immunodeficiency, is essential, and nutritional support is important [108], with a recent large analysis of prognostic factors in community-acquired empyema identifying an admission serum albumin of $\leqslant 30 \mathrm{~g} \cdot \mathrm{L}^{-1}$ as an independent risk factor for mortality [66].

\section{STATEMENT OF INTEREST}

Y.C.G. Lee is a co-investigator of the British Thoracic Society Multicentre Intrapleural Sepsis Trial 2, which is partly funded by Roche Ltd.

\section{REFERENCES}

1 Dunham EK, Graham EA, Mitchell JF et al, Empyema commission. Cases of empyema at Camp Lee, VA. Preliminary report. Am J Med Assoc 1918; 71: 366-373.

2 Davies CW, Kearney SE, Gleeson FV, et al. Predictors of outcome and long-term survival in patients with pleural infection. Am J Respir Crit Care Med 1999; 160: 1682-1687.

3 Ferguson AD, Prescott RJ, Selkon JB, et al. The clinical course and management of thoracic empyema. QJM 1996; 89: 285-289.

4 Maskell NA, Davies CW, Nunn AJ, et al. UK controlled trial of intrapleural streptokinase for pleural infection. $N$ Engl J Med 2005; 352: 865-874

5 Desai G, Amadi W. Three years' experience of empyema thoracis in association with HIV infection. Trop Doct 2001; 31: 106-107.

6 Light RW, Rodriguez RM. Management of parapneumonic effusions. Clin Chest Med 1998; 19: 373-382.

7 Colice GL, Curtis A, Deslauriers J, et al. Medical and surgical treatment of parapneumonic effusions: an evidence-based guideline. Chest 2000; 118: 1158-1171.

8 Roxburgh CS, Youngson GG, Townend JA, et al. Trends in pneumonia and empyema in Scottish children in the past 25 years. Arch Dis Child 2008; 93: 316-318.

9 Hendrickson DJ, Blumberg DA, Joad JP, et al. Five-fold increase in pediatric parapneumonic empyema since introduction of pneumococcal conjugate vaccine. Pediatr Infect Dis J 2008; 27: 1030-1032.

10 Munoz-Almagro C, Jordan I, Gene A, et al. Emergence of invasive pneumococcal disease caused by nonvaccine serotypes in the era of 7-valent conjugate vaccine. Clin Infect Dis 2008; 46: 174-182

11 Van Ackere T, Proesmans M, Vermeulen F, et al. Complicated parapneumonic effusion in Belgian children: increased occurrence before routine pneumococcal vaccine implementation. Eur J Pediatr 2009; 168: 51-58. 
12 Finley C, Clifton J, Fitzgerald JM, et al. Empyema: an increasing concern in Canada. Can Respir J 2008; 15: 85-89.

13 Chapman SJ, Khor CC, Vannberg FO, et al. IkappaB genetic polymorphisms and invasive pneumococcal disease. Am J Respir Crit Care Med 2007; 176: 181-187.

14 Rahman NM, Davies RJO. Effusions from infections: parapneumonic effusion and empyema. In: Light RW, Lee YCG eds. Textbook of Pleural Disease. 2nd Edn. London, Hodder Arnold, 2008; pp. 341-366.

15 Liapakis IE, Light RW, Pitiakoudis MS, et al. Penetration of clarithromycin in experimental pleural empyema model fluid. Respiration 2005; 72: 296-300.

16 Strahilevitz J, Lev A, Levi I, et al. Experimental pneumococcal pleural empyema model: the effect of moxifloxacin. J Antimicrob Chemother 2003; 51: 665-669.

17 Shohet I, Yellin A, Meyerovitch J, et al. Pharmacokinetics and therapeutic efficacy of gentamicin in an experimental pleural empyema rabbit model. Antimicrob Agents Chemother 1987; 31: 982-985.

18 Sahn SA, Reller LB, Taryle DA, et al. The contribution of leukocytes and bacteria to the low $\mathrm{pH}$ of empyema fluid. Am Rev Respir Dis 1983; 128: 811-815.

19 Strange C, Allen ML, Harley R, et al. Intrapleural streptokinase in experimental empyema. Am Rev Respir Dis 1993; 147: 962-966.

20 Sasse SA, Causing LA, Mulligan ME, et al. Serial pleural fluid analysis in a new experimental model of empyema. Chest 1996; 109: 1043-1048.

21 Schopf LF, Fraga JC, Amantea SL, et al. Induction of pleural empyema in rats by thoracentesis with intrapleural pressure monitoring. Pediatr Surg Int 2004; 20: 515-519.

22 Sahn SA, Taryle DA, Good JT Jr. Experimental empyema. Time course and pathogenesis of pleural fluid acidosis and low pleural fluid glucose. Am Rev Respir Dis 1979; 120: 355-361.

23 Mavroudis C, Ganzel BL, Katzmark S, et al. Effect of hemothorax on experimental empyema thoracis in the guinea pig. J Thorac Cardiovasc Surg 1985; 89: 42-49.

24 Zeillemaker AM, Diepersloot RJ, Leguit P. Mesothelial cell activation by micro-organisms. Sepsis 2000; 3: 285-291.

25 Kinnaert P, De Wilde JP, Bournonville B, et al. Direct activation of human peritoneal mesothelial cells by heat-killed microorganisms. Ann Surg 1996; 224: 749-755.

26 Visser CE, Steenbergen JJ, Betjes MG, et al. Interleukin-8 production by human mesothelial cells after direct stimulation with staphylococci. Infect Immun 1995; 63: 4206-4209.

27 van Westreenen M, Pronk A, Diepersloot RJ, et al. Chlamydia trachomatis infection of human mesothelial cells alters proinflammatory, procoagulant, and fibrinolytic responses. Infect Immun 1998; 66: 2352-2355.

28 Visser CE, Brouwer-Steenbergen JJ, Schadee-Eestermans IL, et al. Ingestion of Staphylococcus aureus, Staphylococcus epidermidis, and Escherichia coli by human peritoneal mesothelial cells. Infect Immun 1996; 64: 3425-3428.

29 Broaddus VC, Boylan AM, Hoeffel JM, et al. Neutralization of IL-8 inhibits neutrophil influx in a rabbit model of endotoxininduced pleurisy. J Immunol 1994; 152: 2960-2967.

30 Broaddus VC, Hebert CA, Vitangcol RV, et al. Interleukin-8 is a major neutrophil chemotactic factor in pleural liquid of patients with empyema. Am Rev Respir Dis 1992; 146: 825-830.

31 Kroegel C, Antony VB. Immunobiology of pleural inflammation: potential implications for pathogenesis, diagnosis and therapy. Eur Respir J 1997; 10: 2411-2418.

32 Mohammed KA, Nasreen N, Antony VB. Bacterial induction of early response genes and activation of proapoptotic factors in pleural mesothelial cells. Lung 2007; 185: 355-365.

33 Idell S, Girard W, Koenig KB, et al. Abnormalities of pathways of fibrin turnover in the human pleural space. Am Rev Respir Dis 1991; 144: 187-194.
34 Mohammed KA, Nasreen N, Hardwick J, et al. Mycobacteria induces pleural mesothelial permeability by down-regulating beta-catenin expression. Lung 2003; 181: 57-66.

35 Mohammed KA, Nasreen N, Hardwick J, et al. Bacterial induction of pleural mesothelial monolayer barrier dysfunction. Am J Physiol Lung Cell Mol Physiol 2001; 281: L119-L125.

36 Shetty S, John J, Idell S. Pleural fibrosis. In: Light RW, Lee YCG, eds. Textbook of Pleural Diseases. 2nd Edn. London, Hodder Arnold, 2009; pp. 101-112.

37 Ahmed RA, Marrie TJ, Huang JQ. Thoracic empyema in patients with community-acquired pneumonia. Am J Med 2006; 119: 877-883.

38 Lindstrom ST, Kolbe J. Community acquired parapneumonic thoracic empyema: predictors of outcome. Respirology 1999; 4 173-179.

39 Ruolff KL. Streptococcus. In: Murray PR, Baron EJ, Pfaller MA et al., eds. Manual of Clinical Microbiology. 6th Edn. Washington, American Society for Microbiology, 1995; pp. 299-307.

40 Pratter MR, Irwin RS. Viridans streptococcal pulmonary parenchymal infections. JAMA 1980; 243: 2515-2517.

41 Sarkar TK, Murarka RS, Gilardi GL. Primary Streptococcus viridans pneumonia. Chest 1989; 96: 831-834.

42 Kobashi Y, Mouri K, Yagi S, et al. Clinical analysis of cases of empyema due to Streptococcus milleri group. Jpn J Infect Dis 2008; 61: $484-486$

43 Jerng JS, Hsueh PR, Teng LJ, et al. Empyema thoracis and lung abscess caused by viridans streptococci. Am J Respir Crit Care Med 1997; 156: 1508-1514.

44 Shinzato T, Saito A. A mechanism of pathogenicity of "Streptococcus milleri group" in pulmonary infection: synergy with an anaerobe. J Med Microbiol 1994; 40: 118-123.

45 Shinzato T, Saito A. The Streptococcus milleri group as a cause of pulmonary infections. Clin Infect Dis 1995; 21: Suppl. 3, S238-S243.

46 Maskell NA, Batt S, Hedley EL, et al. The bacteriology of pleural infection by genetic and standard methods and its mortality significance. Am J Respir Crit Care Med 2006; 174: 817-823.

47 Le Monnier A, Carbonnelle E, Zahar JR, et al. Microbiological diagnosis of empyema in children: comparative evaluations by culture, polymerase chain reaction, and pneumococcal antigen detection in pleural fluids. Clin Infect Dis 2006; 42: 1135-1140.

48 Saglani S, Harris KA, Wallis C, et al. Empyema: the use of broad range 16S rDNA PCR for pathogen detection. Arch Dis Child 2005; 90: 70-73.

49 Darkes MJ, Plosker GL. Pneumococcal conjugate vaccine (Prevnar; PNCRM7): a review of its use in the prevention of Streptococcus pneumoniae infection. Paediatr Drugs 2002; 4: 609-630.

50 Lexau CA, Lynfield R, Danila R, et al. Changing epidemiology of invasive pneumococcal disease among older adults in the era of pediatric pneumococcal conjugate vaccine. JAMA 2005; 294: 2043-2051.

51 Dunais B, Bruno P, Carsenti-Dellamonica H, et al. Trends in nasopharyngeal carriage of Streptococcus pneumoniae among children attending daycare centers in southeastern France from 1999 to 2006. Pediatr Infect Dis J 2008; 27: 1033-1035.

52 Millar EV, O'Brien KL, Watt JP, et al. Effect of community-wide conjugate pneumococcal vaccine use in infancy on nasopharyngeal carriage through 3 years of age: a cross-sectional study in a high-risk population. Clin Infect Dis 2006; 43: 8-15.

53 Black S, Shinefield H, Fireman B, et al. Efficacy, safety and immunogenicity of heptavalent pneumococcal conjugate vaccine in children. Northern California Kaiser Permanente Vaccine Study Center Group. Pediatr Infect Dis J 2000; 19: 187-195.

54 Millar EV, Watt JP, Bronsdon MA, et al. Indirect effect of 7-valent pneumococcal conjugate vaccine on pneumococcal colonization among unvaccinated household members. Clin Infect Dis 2008; 47: 989-996.

55 Shafinoori S, Ginocchio CC, Greenberg AJ, et al. Impact of pneumococcal conjugate vaccine and the severity of winter 
influenza-like illnesses on invasive pneumococcal infections in children and adults. Pediatr Infect Dis J 2005; 24: 10-16.

56 Whitney CG, Farley MM, Hadler J, et al. Decline in invasive pneumococcal disease after the introduction of protein-polysaccharide conjugate vaccine. N Engl J Med 2003; 348: 1737-1746.

57 Goldbart AD, Leibovitz E, Porat N, et al. Complicated community acquired pneumonia in children prior to the introduction of the pneumococcal conjugated vaccine. Scand J Infect Dis 2009; 41: 182-187.

58 Bender JM, Ampofo K, Sheng X, et al. Parapneumonic empyema deaths during past century, Utah. Emerg Infect Dis 2009; 15: 44-48.

59 Byington CL, Spencer LY, Johnson TA, et al. An epidemiological investigation of a sustained high rate of pediatric parapneumonic empyema: risk factors and microbiological associations. Clin Infect Dis 2002; 34: 434-440.

60 Hardie W, Bokulic R, Garcia VF, et al. Pneumococcal pleural empyemas in children. Clin Infect Dis 1996; 22: 1057-1063.

61 Buckingham SC, King MD, Miller ML. Incidence and etiologies of complicated parapneumonic effusions in children, 1996 to 2001. Pediatr Infect Dis J 2003; 22: 499-504.

62 Bekri H, Cohen R, Varon E, et al. Streptococcus pneumoniae serotypes involved in children with pleural empyemas in France. Arch Pediatr 2007; 14: 239-243.

63 Byington CL, Korgenski K, Daly J, et al. Impact of the pneumococcal conjugate vaccine on pneumococcal parapneumonic empyema. Pediatr Infect Dis J 2006; 25: 250-254.

64 Bartlett JG, Gorbach SL, Thadepalli H, et al. Bacteriology of empyema. Lancet 1974; 1: 338-340.

65 Koegelenberg CF, Diaconi AH, Bolligeri CT. Parapneumonic pleural effusion and empyema. Respiration 2008; 75: 241-250.

66 Chalmers JD, Singanayagam A, Murray MP, et al. Risk factors for complicated parapneumonic effusion and empyema on presentation to hospital with community-acquired pneumonia. Thorax 2009; 64: 592-597.

67 Chen W, Lin YC, Liang SJ, et al. Hospital-acquired thoracic empyema in adults: a 5-year study. South Med J 2009; 6: 6.

68 Evans AL, Gleeson FV. Radiology in pleural disease: state of the art. Respirology 2004; 9: 300-312.

69 Wu RG, Yuan A, Liaw YS, et al. Image comparison of real-time gray-scale ultrasound and color Doppler ultrasound for use in diagnosis of minimal pleural effusion. Am J Respir Crit Care Med 1994; 150: 510-514.

70 Jones PW, Moyers JP, Rogers JT, et al. Ultrasound-guided thoracentesis: is it a safer method? Chest 2003; 123: 418-423.

71 Chen $\mathrm{CH}$, Chen W, Chen HJ, et al. Transthoracic ultrasonography in predicting the outcome of small-bore catheter drainage in empyemas or complicated parapneumonic effusions. Ultrasound Med Biol 2009; 35: 1468-1474.

72 Kearney SE, Davies CW, Davies RJ, et al. Computed tomography and ultrasound in parapneumonic effusions and empyema. Clin Radiol 2000; 55: 542-547.

73 Roberts JR. Minimally invasive surgery in the treatment of empyema: intraoperative decision making. Ann Thorac Surg 2003; 76: $225-230$

74 Jaffe A, Calder AD, Owens CM, et al. Role of routine computed tomography in paediatric pleural empyema. Thorax 2008; 63: 897-902.

75 Calder A, Owens CM. Imaging of parapneumonic pleural effusions and empyema in children. Pediatr Radiol 2009; 39 527-537.

76 Light RW, MacGregor MI, Ball WC Jr, et al. Diagnostic significance of pleural fluid $\mathrm{pH}$ and $\mathrm{PCO}_{2}$. Chest 1973; 64: 591-596.

77 Light RW, Girard WM, Jenkinson SG, et al. Parapneumonic effusions. Am J Med 1980; 69: 507-512.

78 Porcel JM, Galindo C, Esquerda A, et al. Pleural fluid interleukin-8 and C-reactive protein for discriminating complicated non-purulent from uncomplicated parapneumonic effusions. Respirology 2008; 13: 58-62.

79 Heffner JE, Brown LK, Barbieri C, et al. Pleural fluid chemical analysis in parapneumonic effusions. A meta-analysis. Am J Respir Crit Care Med 1995; 151: 1700-1708.

80 Rahman NM, Mishra EK, Davies HE, et al. Clinically important factors influencing the diagnostic measurement of pleural fluid $\mathrm{pH}$ and glucose. Am J Respir Crit Care Med 2008; 178: 483-490.

81 Porcel JM, Vives M, Cao G, et al. Biomarkers of infection for the differential diagnosis of pleural effusions. Eur Respir J 2009; 34: 1383-1389.

82 Lin MC, Chen YC, Wu JT, et al. Diagnostic and prognostic values of pleural fluid procalcitonin in parapneumonic pleural effusions. Chest 2009; 136: 205-211.

83 Ferrer A, Osset J, Alegre J, et al. Prospective clinical and microbiological study of pleural effusions. Eur J Clin Microbiol Infect Dis 1999; 18: 237-241.

84 Maskell NA, Gleeson FV, Darby $\mathrm{M}$, et al. Diagnostically significant variations in pleural fluid $\mathrm{pH}$ in loculated parapneumonic effusions. Chest 2004; 126: 2022-2024.

85 Davies CW, Gleeson FV, Davies RJ. BTS guidelines for the management of pleural infection. Thorax 2003; 58: ii18-ii28.

86 Keeling AN, Leong S, Logan PM, et al. Empyema and effusion: outcome of image-guided small-bore catheter drainage. Cardiovasc Intervent Radiol 2008; 31: 135-141.

87 Akhan O, Ozkan O, Akinci D, et al. Image-guided catheter drainage of infected pleural effusions. Diagn Interv Radiol 2007, 13: 204-209.

88 Horsley A, Jones L, White J, et al. Efficacy and complications of small-bore, wire-guided chest drains. Chest 2006; 130: 1857-1863.

89 British Thoracic Society. Scottish Intercollegiate Guidelines Network. British guideline on the management of asthma. Thorax 2003; 58: Suppl. 1, i1-i94.

90 Davies HE, Rahman NM, Parker RJ, et al. Use of indwelling pleural catheters for chronic pleural infection. Chest 2008; 133: 546-549.

91 Simmers TA, Jie C, Sie B. Minimally invasive treatment of thoracic empyema. Thorac Cardiovasc Surg 1999; 47: 77-81.

92 Karmy-Jones R, Sorenson V, Horst HM, et al. Rigid thorascopic debridement and continuous pleural irrigation in the management of empyema. Chest 1997; 111: 272-274.

93 Chen KY, Liaw YS, Wang HC, et al. Sonographic septation: a useful prognostic indicator of acute thoracic empyema. J Ultrasound Med 2000; 19: 837-843.

94 Huang HC, Chang HY, Chen CW, et al. Predicting factors for outcome of tube thoracostomy in complicated parapneumonic effusion for empyema. Chest 1999; 115: 751-756.

95 Chin NK, Lim TK. Controlled trial of intrapleural streptokinase in the treatment of pleural empyema and complicated parapneumonic effusions. Chest 1997; 111: 275-279.

96 Lee YC. Ongoing search for effective intrapleural therapy for empyema: is streptokinase the answer? Am J Respir Crit Care Med 2004; 170: 1-2.

97 Diacon $\mathrm{AH}$, Theron J, Schuurmans $\mathrm{MM}$, et al. Intrapleural streptokinase for empyema and complicated parapneumonic effusions. Am J Respir Crit Care Med 2004; 170: 49-53.

98 Froudarakis ME, Kouliatsis G, Steiropoulos P, et al. Recombinant tissue plasminogen activator in the treatment of pleural infections in adults. Respir Med 2008; 102: 1694-1700.

99 Chen LE, Langer JC, Dillon PA, et al. Management of late-stage parapneumonic empyema. J Pediatr Surg 2002; 37: 371-374.

100 Chan DT, Sihoe AD, Chan S, et al. Surgical treatment for empyema thoracis: is video-assisted thoracic surgery "better" than thoracotomy? Ann Thorac Surg 2007; 84: 225-231.

101 Cardillo G, Carleo F, Carbone L, et al. Chronic postpneumonic pleural empyema: comparative merits of thoracoscopic versus open decortication. Eur J Cardiothorac Surg 2009; 36: 914-918. 
102 Sonnappa S, Cohen G, Owens CM, et al. Comparison of urokinase and video-assisted thoracoscopic surgery for treatment of childhood empyema. Am J Respir Crit Care Med 2006; 174: 221-227.

103 Brutsche MH, Tassi GF, Gyorik S, et al. Treatment of sonographically stratified multiloculated thoracic empyema by medical thoracoscopy. Chest 2005; 128: 3303-3309.

104 Waller DA, Martin-Ucar AE. Surgery for pleural diseases. In: Light RW, Lee YCG, eds. Textbook of Pleural Diseases. 2nd Edn. London, Hodder Arnold, 2008; pp. 599-611.
105 Wait MA, Sharma S, Hohn J, et al. A randomized trial of empyema therapy. Chest 1997; 111: 1548-1551.

106 Bilgin M, Akcali Y, Oguzkaya F. Benefits of early aggressive management of empyema thoracis. ANZ J Surg 2006; 76: 120-122.

107 St Peter SD, Tsao K, Harrison C, et al. Thoracoscopic decortication vs tube thoracostomy with fibrinolysis for empyema in children: a prospective, randomized trial. J Pediatr Surg 2009; 44: 106-111.

108 Nwiloh J, Freeman H, McCord C. Malnutrition: an important determinant of fatal outcome in surgically treated pulmonary suppurative disease. J Natl Med Assoc 1989; 81: 525-529. 